\title{
Correction to: Mode-Change PWM Method for Improving Efficiency of 3-Level T-Type PWM Converter
}

\author{
Woo-Cheol Lee ${ }^{1} \cdot$ Tae-Hun Kim ${ }^{2}$
}

Published online: 12 November 2021

(c) The Korean Institute of Electrical Engineers 2021

\section{Correction to: \\ Journal of Electrical Engineering \& Technology https://doi.org/10.1007/s42835-021-00894-3}

Due to an unfortunate misunderstanding during the correction process the corresponding author has been given erroneously. It should be read: Woo-Cheol Lee.

Furthermore, the authors biographies and portraits have been omitted. They should be read:

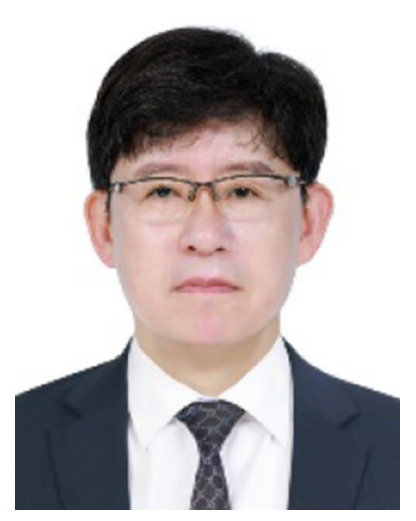

Woo-Cheol Lee He received the B.S. and M.S. and Ph.D. degrees in electrical engineering from Hanyang University, Seoul, Korea, in 1987, 1989, 2001, respectively. From 1988 to 1998 , he was with the R\&D Institute, Hyosung Industries Company Ltd., as a Senior Researcher, Seoul, Korea. He was a Visiting Professor in the department of Electrical Engineering at Virginia Polytechnic Institute and State University, Virginia, USA from 2007 to 2009. Since 2002, he has been with Hankyong National University, Ansung, Korea, where he is a Professor with the Department of Electrical, Electronic and Control Engineering. His research interests are in the areas of power converter, APF, UPS, and electrical drives.

The original article can be found online at https://doi.org/10.1007/ s42835-021-00894-3.

Woo-Cheol Lee

woocheol@hknu.ac.kr

1 School of Electronic and Electrical Engineering, Institute for Information Technology Convergence, Hankyong

National University, Anseong, Korea

2 ADT Company, Anyang-si, Gyeonggi-do, Korea

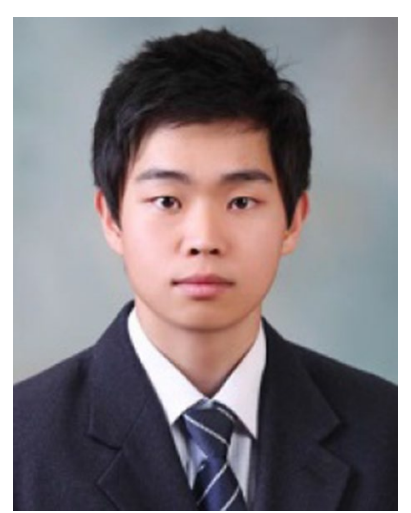

Tae-Hun Kim He received the B.S. and M.S. and Ph.D. degrees in electrical engineering from Hankyong National University, Ansung, Korea, in 2014, 2016, 2020 , respectively. Since 2020 , he has been with the R\&D Institute, Advanced Drive Technology Co., Ltd, Gyeonggi-do, Korea. His research interests are in the areas of power converter, $\mathrm{PFC}$, inverter, and electrical drives.

Publisher's Note Springer Nature remains neutral with regard to jurisdictional claims in published maps and institutional affiliations. 